\title{
Enhanced Position Update Routing using Mobility Prediction and on Demand Learning in Manets
}

\author{
M.Balaganesh \\ Associate Professor \\ Sembodai Rukmani Varatharajan Engineering \\ College \\ Nagapattinam, India
}

\author{
S.Lalitha \\ PG Scholar \\ Sembodai Rukmani Varatharajan Engineering \\ College \\ Nagapattinam, India
}

\begin{abstract}
A MANET is a self configuring infrastructure less networks. It is usually connected by wireless. Each device in a MANET is independently to move in any direction. To maintain neighbor position the geographic location coordinates of the node is a famous method used by most geographic routing protocol for the purpose of periodic broadcasting of beacon packets. If the location information is not available at the node then the geographic method is used. Based on the mobility dynamics of the node and the forwarding patterns, the Adaptiveb Position Update technique is used in the MANET. The location information update process is done by using NS2 simulations of geographic routing protocol.
\end{abstract}

\section{General Terms}

Beacons, broadcast, APU, geographic routing

\section{INTRODUCTION}

An adhoc network is developed by several location based routing protocols. Generally the wireless network uses electromagnetic waves which are implemented with the help of remote information transmission system. It is commonly associated with the help of remote information transmission system. It is commonly associated with the telecommunication networks, which node to node interconnections is implemented without the use of wires. The wireless network is classified into two types. That is infrastructure networks and infrastructure less networks. In infrastructure networks the handoff concept is used. The infrastructure network contains a network with fixed and wired gateways. During the communication process the mobile node can move geographically. It connects with new base station and ready to communicate when it goes out of range of one base station. This is called as handoff. In infrastructure networks all nodes are mobile and can be connected dynamically and also all nodes of these networks are performs as a routers. A wireless ad hoc network is a non centralized wireless network. It can be further classified by their application, they are MANET, Wireless mesh networks, Wireless sensor networks. The adhoc network is not depends on a preexisting infrastructure such as access points in managed wireless networks. Routing in ad-hoc networks contains multiple hops that act as router or relay nodes to forward and receive data packets. Frequently changing network topology and node mobility makes routing in ad-hoc networks is permanently difficult.

Routing is the process of selecting paths in a network to forward the data packets. In packet switching networks, routing directs packet forwarding, the transmission of logically addressed packets from source to destination through intermediate node, generally the hardware devices called routers, bridges, gateways, firewalls, or switches. At a time the routing algorithms use only one network path, but the multiple alternative paths are used by multipath routing techniques

\section{RELATED WORK}

The vast development of ad hoc network includes more number of useful proposals. The following characteristics are useful for focusing the network environments: 1) Need for low latency packet delivery, 2) General communication between host pairs, and 3) A large number of nodes with high density. These characteristics need routing algorithms for keeping per neighbor state. Only the geographic routing algorithms meet these characteristics. The below section describe the detailed definition of few routing concepts which are they used in the adhoc networks.

\subsection{DREAM}

S.Basagni, I.Chlamtac discussed that, a Distance Routing Effect Algorithm for Mobility [2] have an important role they are distance and mobility. This introduces a new definition that says that the routing information are repeated in proactive protocols. At the same time there is no route discovery is required for this protocol. DREAM have a following properties, they are bandwidth, energy efficient, loop free, robust and adaptive to mobility. To analyze these characteristics of DREAM to conclude that the DREAM protocol delivers above 80 percentage of the data message through the computed direction, and also compared with the reactive protocol the average end to end delay of DREAM is decreased.

\subsection{GPSR}

B.Karp and H.T.Kung discussed that, the Greedy Perimeter Stateless Routing Protocol [9] is a wireless datagram's novel routing protocol that make use of position of routers and a packet's destination to create forwarding decisions. Another impressing feature is Small Routing message complexity .Creates less number of routing messages as mobility increases is another attracting feature. In most geographic routing protocol beacons are broadcast periodically for maintaining an accurate neighbor list at each node. Major advantages of GPSR is that it generates routing protocol traffic in a quantity independent of the length of the routes through the network, and therefore creates a constant as well as low volume of routing protocol messages as mobility increases, so doesn't suffer from decreased robustness in finding routes. GPSR represents another powerful lever for scaling routing. Main problems with GPRS are position updating usually is a cost consuming process. Node energy and wireless bandwidth are consumed by each updating. Also increases the risk of packet collision at the medium access 
control (MAC) layer. Packet loss may happen due to packet collisions which in turn affects the routing performance due to decreased accuracy in determining the correct local topology (a lost beacon broadcast is not transmitted again). A lost data packet does get transmitted again (i.e. retransmission), but at the expense of increased end-to-end delay.

\subsection{LAR}

Y.Ko and N.H.Vaidya discussed that, it is mainly used for updating of mobile node host. It limits the search for a new route; this is called as "request zone". This routing result reduces the number of routing messages. Global positioning system provides information to the LAR protocol [11]. Using LAR scheme for route discovery first the sender uses this algorithm to determine a route. As Shown in Fig 1 the sender uses a flooding algorithm to find the route when a route reply is not received within a timeout interval. Node $\mathrm{S}$ needs to find a route to node $\mathrm{D}$.

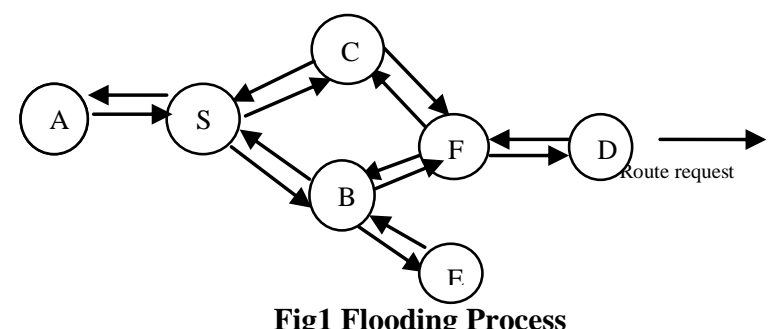

Therefore, node $\mathrm{S}$ broadcasts a route request to its neighbor nodes. If the nodes $\mathrm{B}$ and $\mathrm{C}$ get the route request, then they send it to all of its neighbors. When node $\mathrm{F}$ receives the route request from $\mathrm{B}$, it forwards the request to its neighbors. In the same way if the node $\mathrm{F}$ receives the same request from $\mathrm{C}$, then node $\mathrm{F}$ simply abort the route request. The destination receives a route request message. Upon receiving the route request the destination sends a route reply message to the sender.

Table 1. Comparison between GPSR, DREAM, LAR, APU

\begin{tabular}{|l|l|l|l|l|}
\hline PROTOCOL & $\begin{array}{l}\text { MESSAGE } \\
\text { OVERHEAD }\end{array}$ & DELAY & COST & OTHERS \\
\hline GPSR & Less & Medium & High & $\begin{array}{l}\text { Packet } \\
\text { collision, } \\
\text { packet } \\
\text { loss }\end{array}$ \\
\hline DREAM & Less & Less & $-----------~$ & $\begin{array}{l}\text { Not } \\
\text { scalable, } \\
\text { need } \\
\text { many } \\
\text { beacon } \\
\text { updates }\end{array}$ \\
\hline
\end{tabular}

\begin{tabular}{|l|l|l|l|l|}
\hline LAR & $\begin{array}{l}\text { Reduces } \\
\text { overhead by } \\
\text { limiting } \\
\text { search to } \\
\text { requested } \\
\text { zone only, } \\
\text { reduce traffic, } \\
\text { no need of } \\
\text { hello message } \\
\text { delay } \\
\text { varying } \\
\text { nodes }\end{array}$ & $\begin{array}{l}\text { Uses only } \\
\text { prediction } \\
\text { scheme }\end{array}$ & \\
\hline APU & Less & $\begin{array}{l}\text { Very } \\
\text { less }\end{array}$ & $\begin{array}{l}\text { No cost } \\
\text { factor } \\
\text { considered }\end{array}$ & $\begin{array}{l}\text { Load } \\
\text { balancing } \\
\text { problems }\end{array}$ \\
\hline
\end{tabular}

Here we have compared many previously existing schemes and found APU as one among the better one. It still possesses some problems. Main problem is that it has problem of load balancing. And also shows performance problems in TCP connections. In order to address such problems a new scheme was introduced.

\section{PROPOSED SYSTEM}

The proposed system is based on update the location of mobile node. Based on the mobility dynamics of the nodes and the forwarding patterns in the network the APU [4] strategy dynamically adjusts the beacon [7] update intervals. Based on mobility prediction, APU enables nodes to update their position adaptively to the node mobility and traffic pattern. All nodes are aware of their own position and velocity, all links are bi-directional, the beacon updates include the current location and velocity of the nodes, and data packets can piggyback position and velocity updates and all one-hop neighbors operate in the promiscuous mode and hence can overhear the data packets. Each node broadcasts a beacon informing its neighbors about its presence and its current location and velocity. Following this, in most geographic routing protocols such as GPSR [9], each node periodically broadcasts its current location information. The position information received from neighboring beacons is stored at each node. Based on the position updates received from its neighbors, each node continuously updates its local topology, which is represented as a neighbor list. Only those nodes from the neighbor list are considered as possible candidates for data forwarding. Thus, the beacons play an important part in maintaining an accurate representation of the local topology. APU includes two rules for expressing the beacon update process, which are discussed below.

\section{Mobility Prediction Rule:}

This rule is to express the beacon update process. The goal of this rule is to send the next beacon update from the node when the error occurred between the predicted locations. A simple location Prediction scheme is used. The position information is broadcast only if the previous beacon becomes inaccurate. If the predicted error in the position estimate is greater than a certain threshold then the next beacon is broadcast immediately. The beacon generation is adapts to the frequency by this rule. It determines the characteristics that change the nodes. These characteristics are governed to their motion. 


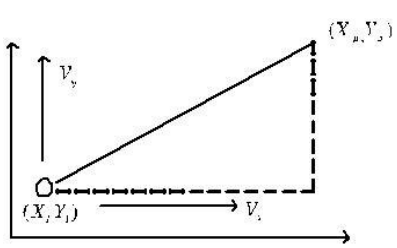

Fig. 2 An example of mobility prediction

As shown in Fig. 2, given the position of node $i$ and its velocity along the $x$ and $y$ axes, at time $T_{l}$, its neighbors, $N(i)$ can estimate the current position of $i$, by using the following equations:

$$
\begin{gathered}
X_{p}{ }^{i}=X_{l}^{i}+\left(T_{c}-T_{l}\right) * V_{x}^{i} \\
Y_{p}{ }^{i}=Y_{l}^{i}+\left(T_{c}-T_{l}\right) * V_{y}^{i}
\end{gathered}
$$

Note that, here $\left(X_{l}^{i}, Y_{l}^{i}\right)$ and $\left(V_{x}^{i}, V_{y}^{i}\right)$ refers to the location and velocity information that was broadcast in the previous beacon from node $i$. Node $i$ uses the same prediction scheme to keep track of its predicted location among its neighbors. Let $\left(X_{a}, Y_{a}\right)$, denote the actual location of node $i$, obtained via GPS or other localization techniques. Node $i$ then computes the deviation $D_{\text {devi }}{ }^{i}$ as follows:

$$
D_{\text {devi }}{ }^{i}=\left(X_{a}^{i}-X_{p}^{i}\right)^{2}+\left(Y_{a}^{i}-Y_{p}^{i}\right)^{2}
$$

If the deviation is greater than a certain threshold, known as the Acceptable Error Range (AER), it acts as a trigger for node $i$ to broadcast its current location and velocity as a new beacon.

2. On Demand Learning rule:

ODL rule allows active nodes that are involved in data forwarding. This rule aims to achieve a node broadcasts beacons on-demand that is in response to data forwarding activities that occur in the area of that node. According to this rule, whenever a node overhears a data transmission from a new neighbor, it broadcasts a beacon as a response. By a new neighbor, we imply a neighbor who is not contained in the neighbor list of this node. A node waits for a small random time interval before responding with the beacon to prevent collisions with other beacons. In other words, a rich neighbor list is maintained at the nodes located in the regions of high traffic load.

\section{Advantages}

GPSR consistently delivers upwards of $94 \%$ of data packets successfully.It is competitive with DSR in this respect on 50node networks at all pause times, and increasingly more successful than DSR as the number of nodes increases, as demonstrated on 112-node and 200-node networks.GPSR generates routing protocol traffic in a quantity independent of the length of the routes through the network, and therefore generates a constant, low volume of routing protocol messages as mobility increases, yet doesn't suffer from decreased robustness in finding routes.

\section{NETWORK SIMULATOR 2 (NS2)}

NS2 is an open-source simulation tool that runs on Linux. It is a discreet event simulator targeted at networking research and provides substantial support for simulation of routing, multicast protocols and IP protocols, such as UDP, TCP over wired and wireless (local and satellite) networks. It has many advantages that make it a useful tool, such as support for multiple protocols and the capability of graphically detailing network traffic. Additionally, NS2 supports several algorithms in routing and queuing. Queuing algorithms include fair queuing, deficit round-robin and FIFO. NS2 started as a variant of the REAL network simulator in 1989. REAL is a network simulator originally intended for studying the dynamic behavior of flow and congestion control schemes in packet-switched data network. NS2 is available on several platforms such as FreeBSD, Linux, SunOS and Solaris. NS2 also builds and runs under Windows.

Node Methods: Configuring the Node

Procedures to configure an individual node can be classified into:

- Control functions

- Address and Port number management,unicast routing functions

- Agent management

- Adding neighbors

\subsection{SIMULATION PROCEDURE}

Run the script by typing at the Konsole ns filename.tcl

On completion of the run, Trace output file "filename-out.tr" and nam output file "filename-out.nam" are created. Running filename-out.nam, the mobile nodes moving in nam window can be seen. The number of nodes is set and the percentage of active senders is determined. The active senders start informing the network about its presence and begin sending data according to the random progress method.

The finish procedure is given as

proc finish \{\}\{

\$ns flush-trace

close $\$ \mathrm{f}$

close \$nf

exec nam -r filename.nam

$\&$ exit $0 \quad\}$

In the finish procedure, the trace file buffer is cleared and graphs are generated in the terminal in a pipelined manner. $\$ \mathrm{nf}$ is used to close the trace field. Now the animator field is generated using command exec nam filename.nam To run the file \$ns run command is used and the tcl script is executed. To execute the graph exec ns graph.tcl command is used.

\section{RESULTS AND DISCUSSIONS}

The proposed method addresses the congestion issues considering delay, packet loss and routing overhead. In order to evaluate the performance of the multipath video multicasting and to compare it with conventional multicasting, the below parameters are configured in the network simulator.

$\begin{array}{ll}\text { Packet Size } & : 2000 \text { bytes } \\ \text { No. of Nodes } & : 100 \\ \text { Protocol Used }: \text { AODV } \\ \text { Dimension } \quad: 1000 * 1000 \\ \text { Channel Type }: \text { Wireless channel IEEE } 802.11 \\ \text { Queue Type } \quad: \text { Drop Tail/PriQueue } \\ \text { Antenna } \quad: \text { Omni Antenna } \\ \text { Protocol } \quad: \text { TCP } \\ \text { Mobility } \quad: 10 \mathrm{~m} / \mathrm{s}\end{array}$




\subsection{SIMULATION RESULTS}

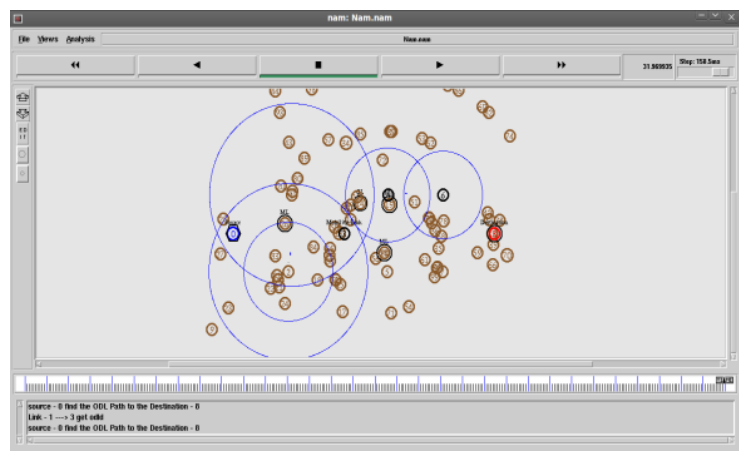

Fig 3:Position Update

The Fig 3 shows that the initial position of nodes

In this simulation the data packet is transmitted in multipath to multiple receivers.

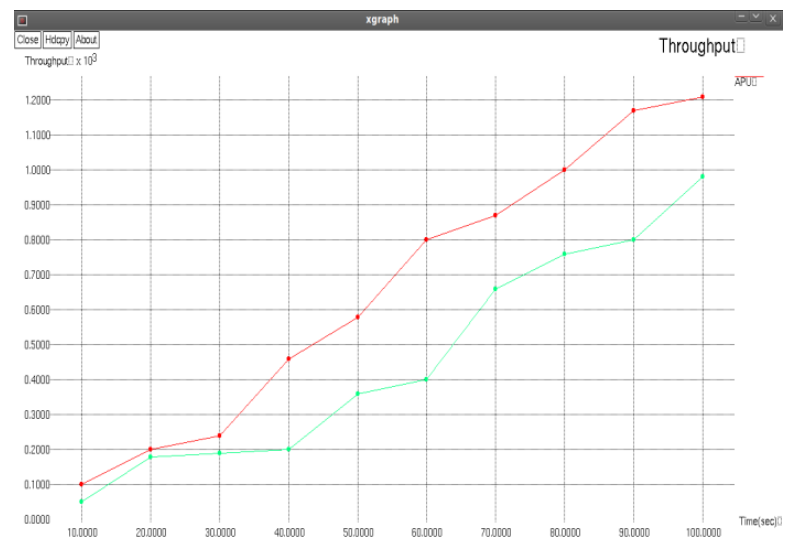

Fig 4: Throughput

The Fig 4 shows that the throughput of the adaptive position updating and periodic broadcasting where throughput is high for APU since number of successful transmissions are increased.

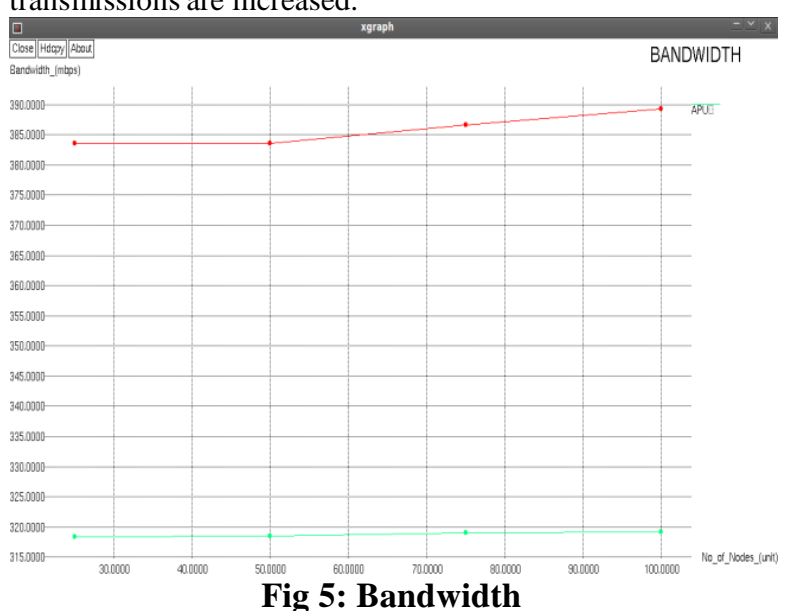

The Fig 5 shows that the bandwidth usage of the Adaptive Position Update and the Periodic broadcasting. Depends on the above simulation the APU is effectively utilize the bandwidth.

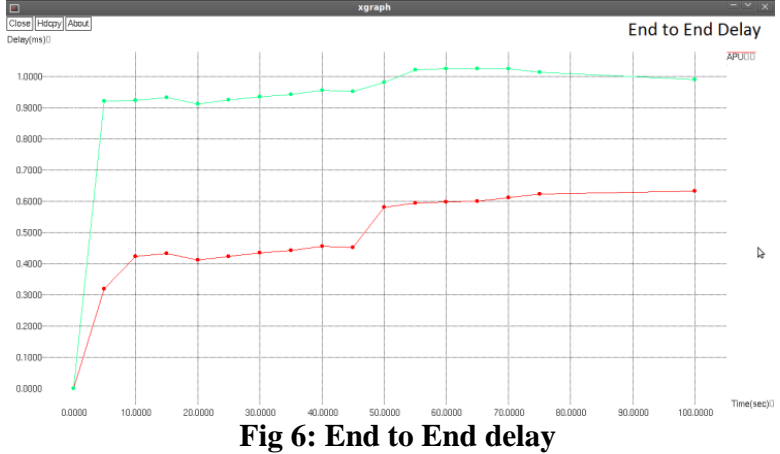

The Fig 6 shows that the end to end delays comparison of periodic broadcasting and adaptive position updating of the nodes. For periodic broadcasting the delay is more.

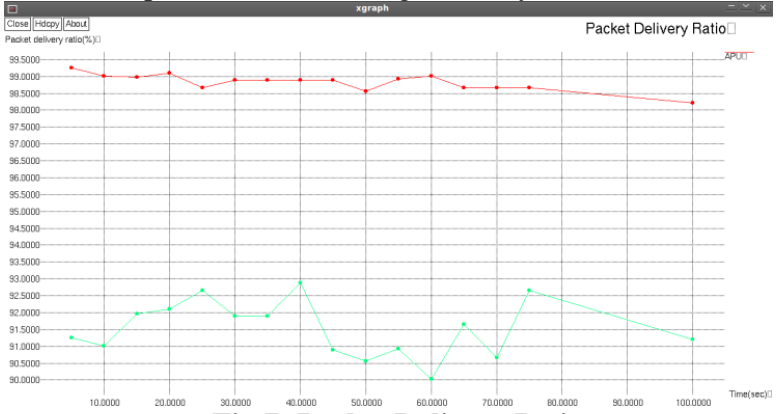

Fig 7: Packet Delivery Ratio

The Fig 7 shows that the packet delivery ratio of the periodic broadcasting and adaptive position updating with respect to time and also it shows that the packet delivery ratio is efficient for APU.

Table 2. Analysis of Simulation Results

\begin{tabular}{|l|l|l|l|}
\hline \multicolumn{4}{|c|}{ ADAPTIVE POSITION UPDATE } \\
\& \\
\multicolumn{3}{|c|}{ PERIODIC BROADCASTING } \\
\hline Throughput & Bandwidth & $\begin{array}{l}\text { End to End } \\
\text { Delay }\end{array}$ & $\begin{array}{l}\text { Packet } \\
\text { Delivery } \\
\text { Ratio }\end{array}$ \\
\hline High & $\begin{array}{l}\text { Effectively } \\
\text { utilized by } \\
\text { CPU }\end{array}$ & More & $\begin{array}{l}\text { Efficient for } \\
\text { APU }\end{array}$ \\
\hline
\end{tabular}

\section{CONCLUSION}

The need to adapt the beacon update policy employed in geographic routing protocols to the node mobility dynamics and the traffic load is identified. We proposed the Adaptive Position Update strategy to address these problems. The APU scheme employs two mutually exclusive rules. The MP rule uses mobility prediction to estimate the accuracy of the location estimate and adapts the beacon update interval accordingly, instead of using periodic beaconing. The ODL rule allows nodes along the data forwarding path to maintain an accurate view of the local topology by exchanging beacons in response to data packets that are overheard from new neighbors. The beacon overhead and local topology accuracy of APU and validated the analytical model with the simulation results. GPSR and have compared it with other related beaconing strategies using extensive NS-2 simulations for varying node speeds and traffic load. 


\section{REFERENCES}

[1] M.Balaganesh, and S.Lalitha, "A Survey of Adaptive Position Update for Geographic Routing in Mobile Adhoc Networks" IJACT Vol 2, no.6, pp-43-46, Dec 2013.

[2] S.Basagni, I.Chlamtac, V.Syrotiuk and B.Woodward "A distance routing effect algorithm for mobility (DREAM)," in Proceedings of the Fourth Annual ACM/IEEE International Conference on Mobile Computing and Networking, MobiCom '98, (Dallas, Texas), August 1998.

[3] L.S.Blazevic, Giordano and J.Y.LeBoudec, "A Location Based Routing Method for Mobile Ad Hoc Networks", IEEE Trans. Mobile Computing, vol. 4, no. 2, pp. 97-110, 2005.

[4] Q.Chen, S.SKanhere, and M.Hassan, "Adaptive Position Update for Geographic Routing in Mobile Ad Hoc Networks," IEEE Transactions on Mobile Computing, vol. 12, no. pp- 489-501, March 2013.

[5] Q. Chen, S.S. Kanhere, and M. Hassan, "Mobility and Traffic Adaptive Position Update for Geographic Routing," Technical Report UNSW-CSE-TR-1002, School of Computer Science and Eng., Univ. of New South Wales, ftp://ftp.cse.unsw.edu.au/pub/ doc/papers/UNSW/1002.pdf, 2010.

[6] L.M.Feeney. And M.Nilsson, "Investigating the Energy Consumption of a Wireless Network Interface in an Ad HocNetworking Environment" Proc. IEEE INFOCOM, pp. 15481557
[7] M.Heissenbuttel, T.Braun, W.Walchli, and T.Bernoulli. "Evaluating of Limitations and Alternatives in Beaconing", Ad Hoc Networks, vol. 5, no. May 2005

[8] D.Johnson, Y.Hu, and D.Maltz. "The Dynamic Source Routing Protocol (DSR) for Mobile Ad Hoc Networks for IPv4", IETF RFC 4728, vol. 15, pp. 153-181, Feb. 2007

[9] B.Karp, and H.T.Kung, "GPSR: Greedy Perimeter Stateless Routing for Wireless Networks" Proc. ACM Mobi Com, pp. 243254, 2000.

[10] Y.Kim, R.Govindan, B.Karp, and S.Shenker, "Geographic Routing Made Practical" Proc. Second Conf. Symp. Networked Systems Design and Implementation, pp. 217-230, 2005

[11] Y.Ko, and N.H.Vaidya, "Location-aided routing (LAR) in mo- bile ad hoc networks" in Proceedings of the ACM/IEEE Inter- national Conference on Mobile Computing and Networking (Mobi- com), pp. 66-75, 1998.

[12] J.Li, J.Jannotti, D.S.J.D.Couto, D.R.Karger, and Morris, $\mathrm{R}$ "A Scalable Location Service for Geographic Ad Hoc Routing”Proc.ACM MobiCom, pp. 120-130, 2000

[13] D.Maltz, J.Broch,J.Jetcheva, and D.Johnson, "The effects of on-demand behavior in routing protocols for multihop wireless ad hoc networks" IEEE Journal on Selected Areas in Communications 17, 8,14391453, August 1999

[14] A.Rao, S.Ratnasamy, C.Papadimitriou, S.Shenker, and I.Stoica, "Geographic Routing without Location Information’ Proc. ACM MobiCom, pp. 96-108 